\title{
Treatment for mild cognitive impairment: a systematic review and meta-analysis
}

\author{
Donna Fitzpatrick-Lewis MSW, Rachel Warren MA, Muhammad Usman Ali MD, Diana Sherifali PhD, \\ Parminder Raina $\mathrm{PhD}$
}

See also www.cmaj.ca/lookup/doi/10.1503/cmaj.141165

Abstract

Background: The effectiveness of treatments for mild cognitive impairment is uncertain. The aim of this review was to evaluate the effectiveness and harms of treatment for mild cognitive impairment in adults 65 years of age and older.

Methods: We searched MEDLINE, Embase and Cochrane Central (December 2012-December 2014); citations from 2 systematic reviews were considered for inclusion. We included randomized controlled trials involving community-dwelling adults aged 65 years and older with a diagnosis of mild cognitive impairment. Studies reporting on cognition, function, behaviour, global status, mortality and adverse events for treatment with pharmacologic and nonpharmacologic interventions were included.

Results: Seventeen studies were included. Cholinesterase inhibitor studies evaluating cognition (Alzheimer's Disease Assessment Scale, cognition subscale) showed no difference between intervention and control groups (mean difference [MD] $-0.33,95 \% \mathrm{CI}$ -0.73 to 0.06 ]; one behavioural study showed no significant effect on cognition (Alzheimer's Disease Assessment Scale, cognition subscale) for the intervention group when compared to controls (MD $-0.60,(95 \% \mathrm{Cl}-1.44$ to 0.24$)$, and one study on vitamin $\mathrm{E}$ showed no difference between intervention and control groups (MD 0.85, 95\% Cl -0.32 to 2.02). With the Mini-Mental State Examination, cholinesterase inhibitors showed no difference between intervention and control groups ( $\mathrm{MD} 0.17,95 \% \mathrm{Cl}-0.13$ to 0.47 ); behavioural studies showed a significant difference favouring intervention (MD 1.01, 95\% $\mathrm{Cl} 0.25$ to 1.77 ), and studies of dietary supplements and/or vitamins showed no difference between intervention and control groups (MD 0.20, 95\% $\mathrm{Cl}-0.04$ to 0.43 ). Pharmacologic studies showed no difference in serious adverse events (risk ratio $0.98,95 \% \mathrm{Cl} 0.86$ to 1.10 ). No serious adverse events were reported for nonpharmacologic interventions.

Interpretation: Treatment of mild cognitive impairment with cholinesterase inhibitors showed no benefit when compared with a control group. A small cognitive benefit was observed using behavioural therapies when compared with the control group. However, the clinical significance of this small benefit remains uncertain. The current evidence does not support the use of cholinesterase inhibitors for treating mild cognitive impairment, and future high-quality research using a standardized approach is needed to affirm the finding of a small benefit on cognition that was observed for behavioural interventions. Registration: PROSPERO no. CRD42014015431.

\footnotetext{
n 2011, an estimated 747000 Canadians were living with some type of cognitive impairment, ${ }^{1}$ whereas about $10 \%$ of Canadians aged 65 years and older have some form of mild cognitive impairment that is often undetected. ${ }^{2}$ In 2001, the Canadian Task Force for Preventive Health Care reported insufficient evidence to make a recommendation for or against screening for cognitive impairment in Canadians. ${ }^{2}$ In 2014, the US Preventive Services Task Force similarly reported that the evidence was insufficient to make a recommendation on screening older adults for cognitive impairment. ${ }^{3}$

Over the past 25 years, the definition of mild cognitive impairment has evolved from a broad definition of a set of symptoms related to memory and thinking skills between nor-
}

mal cognition and dementia ${ }^{4}$ to a classification by cognitive domains and mild cognitive impairment subtypes based on the type of thinking skills affected (i.e., amnestic mild cognitive impairment and nonamnestic mild cognitive impairment). ${ }^{5}$ However, the operationalization of mild cognitive impairment

Competing interests: None declared.

This article has been peer reviewed.

Correspondence to: Donna Fitzpatrick-Lewis, fitzd@mcmaster.ca; Parminder Raina, praina @ mcmaster.ca

CMAJ Open 2015. DOI:10.9778/cmajo.20150057 
definitions is challenging, with questions about the validity and existence of a condition of mild cognitive impairment rather than a set of symptoms. ${ }^{6}$

Treatment of cognitive impairment is also contentious. In 2013, the US Preventive Services Task Force review on screening for cognitive impairment evaluated both pharmacologic and nonpharmacologic interventions for the treatment of cognitive impairment and found evidence on the benefit of treating cognitive impairment, including mild to moderate dementia and Alzheimer disease. However, they reported a lack of clarity on the clinical importance of this evidence. ${ }^{7}$ Another high-quality systematic review by Tricco and colleagues ${ }^{8}$ evaluated the treatment of mild cognitive impairment specifically using pharmacologic treatments and concluded that the evidence did not support the use of cognitive enhancers for people with mild cognitive impairment. The aim of this review is to bridge the research gap by evaluating the safety and effectiveness of the pharmacologic and nonpharmacologic treatments available for mild cognitive impairment.

\section{Methods}

This manuscript reports on selected outcomes; please see the full technical report (forthcoming at http://canadiantaskforce. ca) for full details. We have used similar methods in other publications (see http://canadiantaskforce.ca/). This systematic review adheres to the Preferred Reporting Items for Systematic Reviews and Meta-Analyses (PRISMA) checklist. ${ }^{9}$

\section{Key question 1}

Do pharmacologic or nonpharmacologic interventions for mild cognitive impairment in community-dwelling adults ( $\geq 65 \mathrm{yr}$ of age) improve cognition (primary outcome), or function, behaviour, global status or mortality (secondary outcomes)?

\section{Key question 2}

What are the serious adverse events, including hospitalization or death, of pharmacologic or nonpharmacologic interventions for mild cognitive impairment?

\section{Search strategy}

Our search was based on the treatment search conducted by Lin and colleagues. ${ }^{7}$ Our librarian reviewed this search and found it comprehensive and of good quality. For our review, we narrowed the search by excluding the general terms for dementia and narrowing the focus of our search to mild cognitive impairment using the subject heading or text words for mild cognitive impairment. We searched MEDLINE, Embase and the Cochrane Central Register of Controlled Trials databases for the period December 2012 to December 2014 (Appendix 1, available at www.cmajopen.ca/content/3/4/E419/suppl/DC1). We updated this search in August 2015.

\section{Eligibility criteria}

We included English or French language studies involving community-dwelling adults aged 65 years and older with a diagnosis of mild cognitive impairment (however it was defined). We included randomized controlled trials (RCTs) of pharmacologic and nonpharmacologic treatments for mild cognitive impairment ( $\geq 6$ mo in duration for benefits studies; no restrictions on harms studies). Outcomes of interest were based on those selected by Tricco and colleagues: ${ }^{8}$ cognition, measured by the Mini-Mental State Examination or Alzheimer's Disease Assessment Scale, cognition subscale; function, measured by the Alzheimer's Disease Cooperative Study activities of daily living inventory; behaviour, measured by the Neuropsychiatric Inventory; global status, measured by the Clinician's Intervention-based Impression of Change plus Caregiver; and mortality and serious adverse events.

\section{Study selection, data abstraction and quality assessment}

We screened the citations found through our search, as well as citations from the systematic review by Lin and colleagues ${ }^{7}$ and the systematic review by Tricco and colleagues. ${ }^{8}$ Titles and abstracts were reviewed in duplicate; articles marked for inclusion by either team member went on to full-text relevance testing. Full-text screening was completed independently by 2 team members, with consensus required for inclusion or exclusion.

One team member completed full data extraction and an assessment of risk of bias using the Cochrane risk-of-bias tool, ${ }^{10}$ and a second team member verified all data. Conflicts were resolved through discussion or by a third team member. For the outcomes of cognition and serious adverse events, we evaluated the quality of the body of evidence using the Grading of Recommendation, Assessment, Development and Evaluations (GRADE) method using GRADEPro software (version 3.6 for Windows, available at http://ims.cochrane.org/revman/other -resources/gradepro/download). ${ }^{11}$

\section{Data synthesis}

For continuous outcomes, we used change from baseline to immediate posttreatment data, and extracted data were metaanalyzed when appropriate. We used the random effects models with inverse variance method to generate the summary measures of effect in the form of mean difference (MD). ${ }^{12}$ For studies that did not report standard deviation (SD), we calculated this value from the reported standard error (SE) of the mean, or from the $95 \%$ confidence intervals (CIs) using equations provided in the Cochrane handbook for systematic reviews of interventions. ${ }^{13}$ For studies that provided neither SD nor SE for the follow-up data, we imputed the SD from the baseline values or other included studies using recommended methods. ${ }^{14}$ We employed the Cochran's $Q$ test $(\alpha=0.05)$ to detect statistical heterogeneity and the $I^{2}$ statistic to quantify the magnitude of statistical heterogeneity between studies (where $I^{2}>50 \%$ and $I^{2}>75 \%$ represented moderate and substantial heterogeneity, respectively).

\section{Results}

We screened 566 unique citations and included 17 studies (Figure 1). ${ }^{15}$ Twelve RCTs answered the question of benefits 
of treatment for mild cognitive impairment (Table 1; Table S1, available in Appendix 2 at www.cmajopen.ca/content/3/4/ E419/suppl/DC1), ${ }^{16-27}$ and 11 answered the question on harms of treatment for mild cognitive impairment. ${ }^{16,17,20,24,25,27-32}$ Riskof-bias ratings are provided in Table 2.

\section{Benefits of treatment}

Four pharmacologic studies evaluating the effect of cholinesterase inhibitors were identified: 1 study examined riv- astigmine $(3-12 \mathrm{mg} / \mathrm{d}),{ }^{16} 1$ study examined galantamine $(8-12 \mathrm{mg} / \mathrm{d})^{17}$ and 2 studies examined donepezil $(10 \mathrm{mg} / \mathrm{d}) .^{24,27}$ These studies took place primarily in Canada and the United States, although 1 study $^{16}$ took place across 14 countries. Five studies focused on behavioural interventions: ${ }^{18-21,25} 3$ on exercise interventions, ${ }^{18,20,25} 1$ on holistic cognitive rehabilitation; ${ }^{19}$ and 1 on a multimodal intervention with stimulation and cognitive training. ${ }^{21}$ These studies took place in Japan, Greece, China and Argentina. Four studies evaluated the benefits of

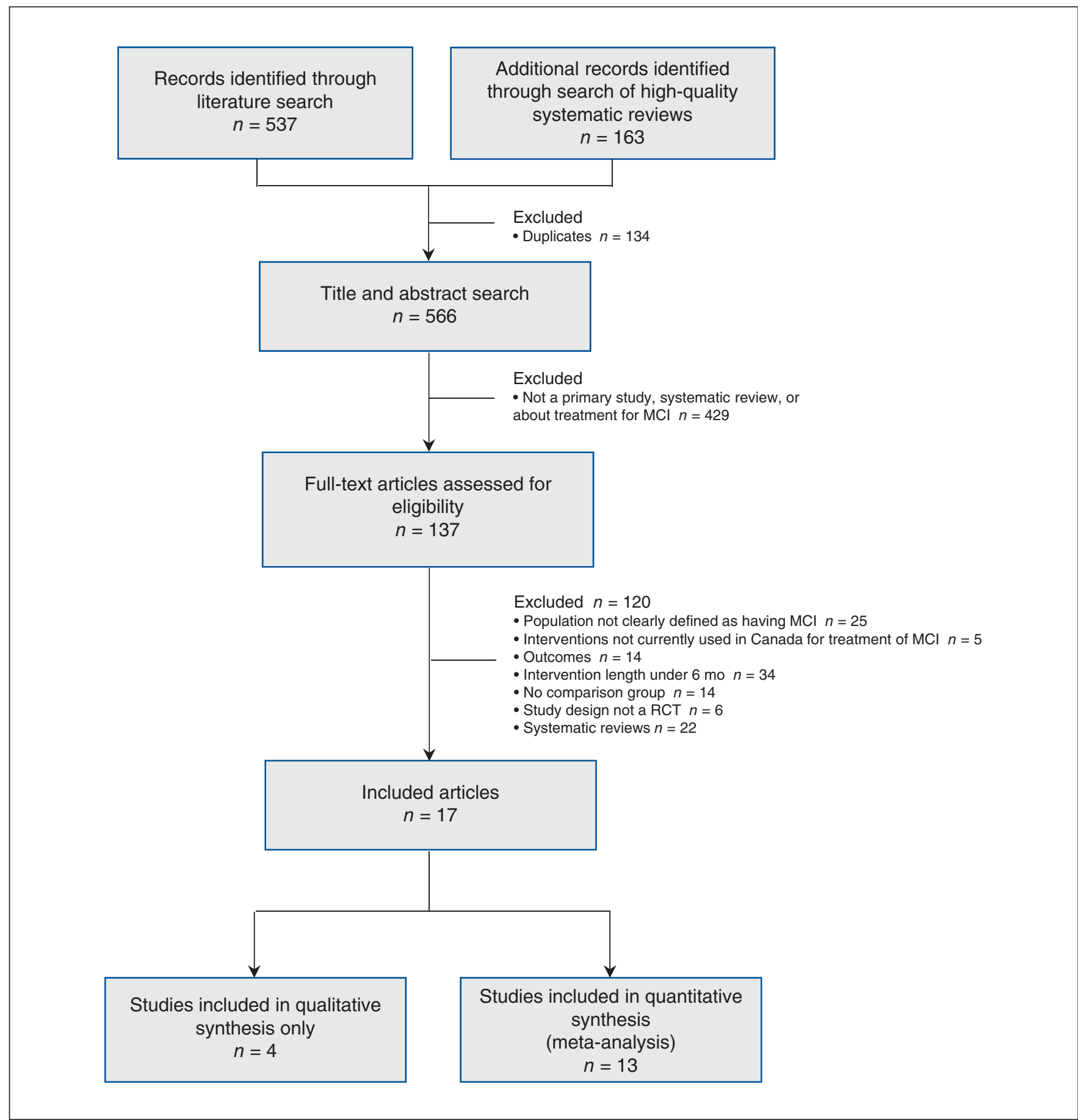

Figure 1: Identification of eligible studies. $\mathrm{MCl}=$ mild cognitive impairment, $\mathrm{RCT}$ = randomized controlled trial. 


\section{OPEN}

Research

dietary supplements or vitamins..$^{22,23,26,27}$ Two studies evaluated the effects of vitamin $\mathrm{E}$ (one using $2000 \mathrm{IU}$ in combination with a multivitamin that contained 15 IU vitamin $\mathrm{E}$ taken daily ${ }^{27}$ and the other using $300 \mathrm{mg}$ in combination with $400 \mathrm{mg}$ of vitamin $\mathrm{C}$ taken daily ${ }^{23}$ ). One study evaluated a combination of docosahexaenoic $(1.3 \mathrm{~g})$ and eicosapentaenoic acid $(0.45 \mathrm{mg})$ taken daily ${ }^{22}$ and another evaluated vitamin $\mathrm{B}$ (0.8 mg folic acid, $0.5 \mathrm{mg}$ vitamin B12 and $20 \mathrm{mg}$ vitamin B6) taken daily. ${ }^{26}$ These studies took place in the US and Canada, Malaysia, Iran and the UK.

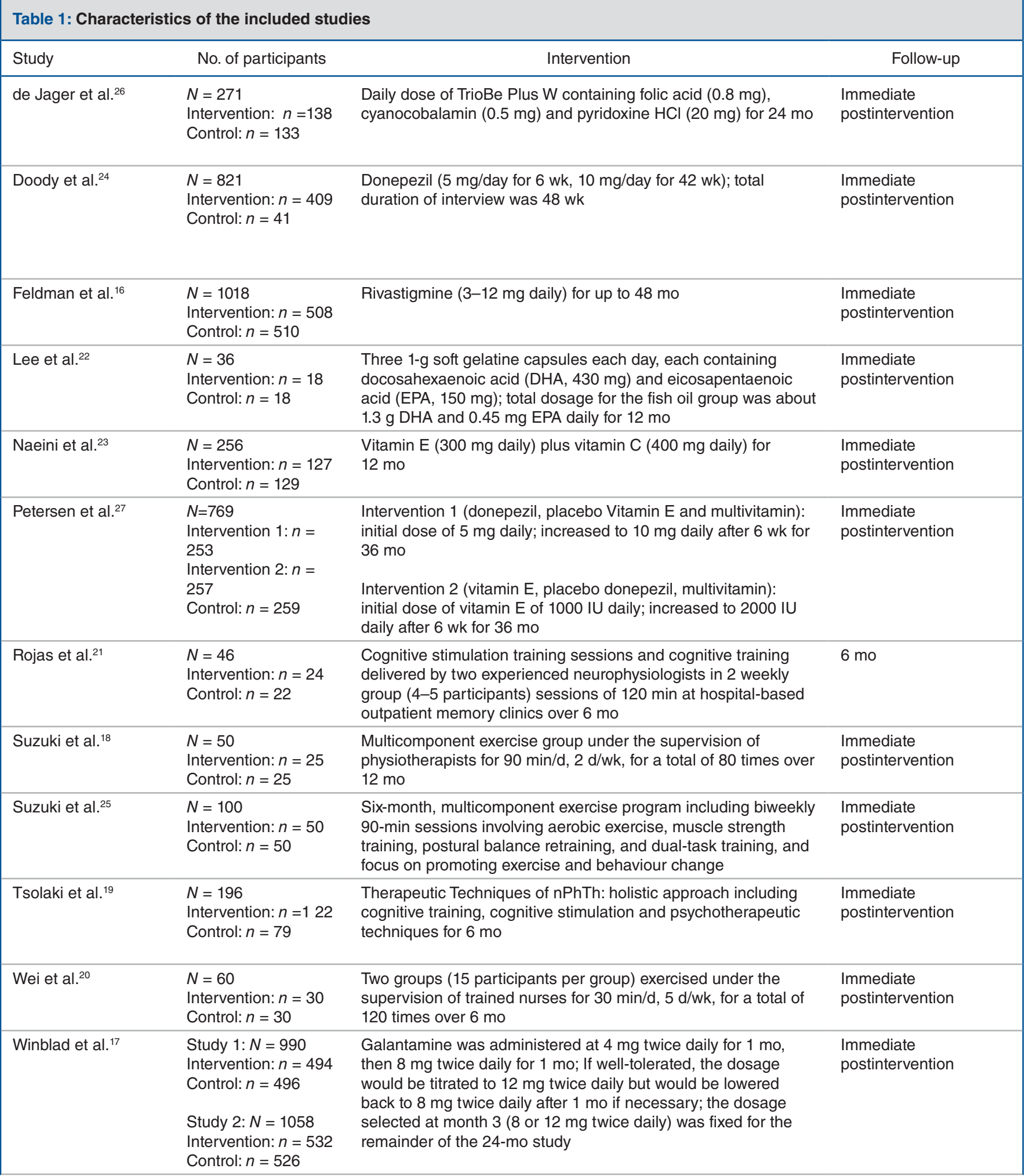




\section{Cognition}

The quality of this body of evidence was graded low to moderate (Appendix 3, available at www.cmajopen.ca/content/ 3/4/E419/suppl/DC1).

\section{Alzheimer's Disease Assessment Scale, cognition subscale}

We used the data from the 4 pharmacologic studies involving donepezil, rivastigmine and galantamine, ${ }^{16,17,24,27}$ which had a total of 2078 participants in the intervention groups and 2110 in the control groups. The pooled-effect estimate showed no difference between intervention and control groups (MD $-0.33,95 \%$ CI -0.73 to 0.06 ; Figure 2). The test for subgroup difference across 3 pharmacologic intervention types was also nonsignificant $(p=0.55)$, with no intervention type showing significant difference in effect when compared with controls (Figure 2). One study using behavioural interventions (multicomponent exercise) and the effect estimate showed no difference between the intervention and control groups ( $\mathrm{MD}-0.60$, 95\% CI -1.44 to 0.24; Figure S1 in Appendix 4, available at www.cmajopen.ca/content/3/4/E419/suppl/DC1). ${ }^{17}$

One study involving vitamin E (2000 IU) in combination with a multivitamin (containing 15 IU vitamin E) taken daily showed an effect estimate of no difference between intervention and control groups (MD 0.85, 95\% CI -0.32 to 2.02; Figure S2 in Appendix 4). ${ }^{27}$

\section{Mini-Mental State Examination}

We used the data from 3 of the pharmacologic studies (2 involving donepezil and 1 involving rivastigmine), ${ }^{16,24,27}$ which included a total of 1140 participants in the intervention groups and 1147 in the control groups. The pooled effect estimate showed no difference between the intervention and control groups (MD 0.17, 95\% CI -0.13 to 0.47; Figure 3). The test for subgroup difference across 2 pharmacologic intervention types was also nonsignificant $(p=0.65)$, with no intervention type showing significant difference in effect when compared with controls (Figure 3).

Five studies focused on behavioural interventions (3 involving multicomponent exercise programs and 2 involving cognitive training and rehabilitation). ${ }^{18-21,23}$ The pooled effect estimate showed a significant difference favouring intervention when compared with controls (MD 1.01, 95\% CI 0.25 to 1.77; Figure S3 in Appendix 4). Three of these studies (2 involving cognitive training and rehabilitation and 1 involving handball training exercise) showed a significant difference in effect favouring intervention when compared with controls (Figure S3 in Appendix 4). ${ }^{19-21}$

Four studies evaluated the benefits of the use of dietary supplements or vitamins for mild cognitive impairment when compared with placebo. ${ }^{22,23,26,27}$ Two of the studies evaluated the effects of vitamin E (1 study involved 2000 IU in combination with a multivitamin containing $15 \mathrm{IU}$ vitamin $\mathrm{E}$ taken daily ${ }^{27}$ and the other involved $300 \mathrm{mg}$ in combination with $400 \mathrm{mg}$ of vitamin $\mathrm{C}$ taken daily $\left.{ }^{23}\right)$. One study evaluated a combination of docosahexaenoic $(1.3 \mathrm{~g})$ and eicosapentaenoic acid $(0.45 \mathrm{mg})$ taken daily ${ }^{22}$ and another evaluated vitamin B (0.8 $\mathrm{mg}$ folic acid, $0.5 \mathrm{mg}$ vitamin B12 and $20 \mathrm{mg}$ vitamin $\mathrm{B} 6$ ) taken daily. ${ }^{26}$ All 4 studies measured cognition using the MiniMental State Examination, and the pooled effect estimate

Table 2: Appraisal of the risk of bias of the included studies using the Cochrane risk-of-bias tool

\begin{tabular}{|c|c|c|c|c|c|c|c|}
\hline Study & $\begin{array}{l}\text { Sequence } \\
\text { generation }\end{array}$ & $\begin{array}{c}\text { Allocation } \\
\text { concealment }\end{array}$ & Blinding & $\begin{array}{l}\text { Incomplete } \\
\text { outcome data }\end{array}$ & $\begin{array}{l}\text { Selective } \\
\text { reporting }\end{array}$ & Other & Overall \\
\hline Doody et al..$^{24}$ & L & L & L & L & L & $\mathrm{H}$ & L \\
\hline Feldman et al. ${ }^{16}$ & L & L & L & $\mathrm{H}$ & L & $\mathrm{H}$ & $U$ \\
\hline Petersen et al. ${ }^{27}$ & U & $U$ & L & L & L & L & $U$ \\
\hline Salloway et al. ${ }^{28}$ & $U$ & $\mathrm{U}$ & L & $\mathrm{H}$ & L & $\mathrm{H}$ & $U$ \\
\hline Winblad et al. ${ }^{17}$ & $U$ & $U$ & L & L & L & $\mathrm{H}$ & $U$ \\
\hline Suzuki et al. ${ }^{18}$ & U & $U$ & L & L & L & $\mathrm{H}$ & $U$ \\
\hline Tsai et al. ${ }^{29}$ & L & $U$ & L & L & L & $\mathrm{H}$ & $U$ \\
\hline de Jager et al. ${ }^{26}$ & L & L & L & L & L & $U$ & L \\
\hline Tsolaki et al. ${ }^{19}$ & U & $U$ & U & L & L & L & $U$ \\
\hline van Uffelen et al. ${ }^{30}$ & L & L & L & L & L & $\mathrm{H}$ & L \\
\hline Wei et al. ${ }^{20}$ & U & $U$ & $\mathrm{H}$ & $U$ & L & $U$ & $U$ \\
\hline Suzuki et al. ${ }^{25}$ & L & L & L & L & L & L & L \\
\hline Rojas et al. ${ }^{21}$ & $U$ & $U$ & L & $\mathrm{H}$ & L & $\mathrm{H}$ & $U$ \\
\hline Lee et al. ${ }^{22}$ & L & $U$ & L & L & L & $\mathrm{H}$ & $U$ \\
\hline Naeini et al. ${ }^{23}$ & $U$ & $U$ & L & L & L & L & U \\
\hline Rondanelli et al. ${ }^{31}$ & $U$ & $U$ & L & L & L & $\mathrm{H}$ & $U$ \\
\hline Yakoot et al. ${ }^{32}$ & L & L & L & L & L & $\mathrm{H}$ & L \\
\hline
\end{tabular}




\section{Research}

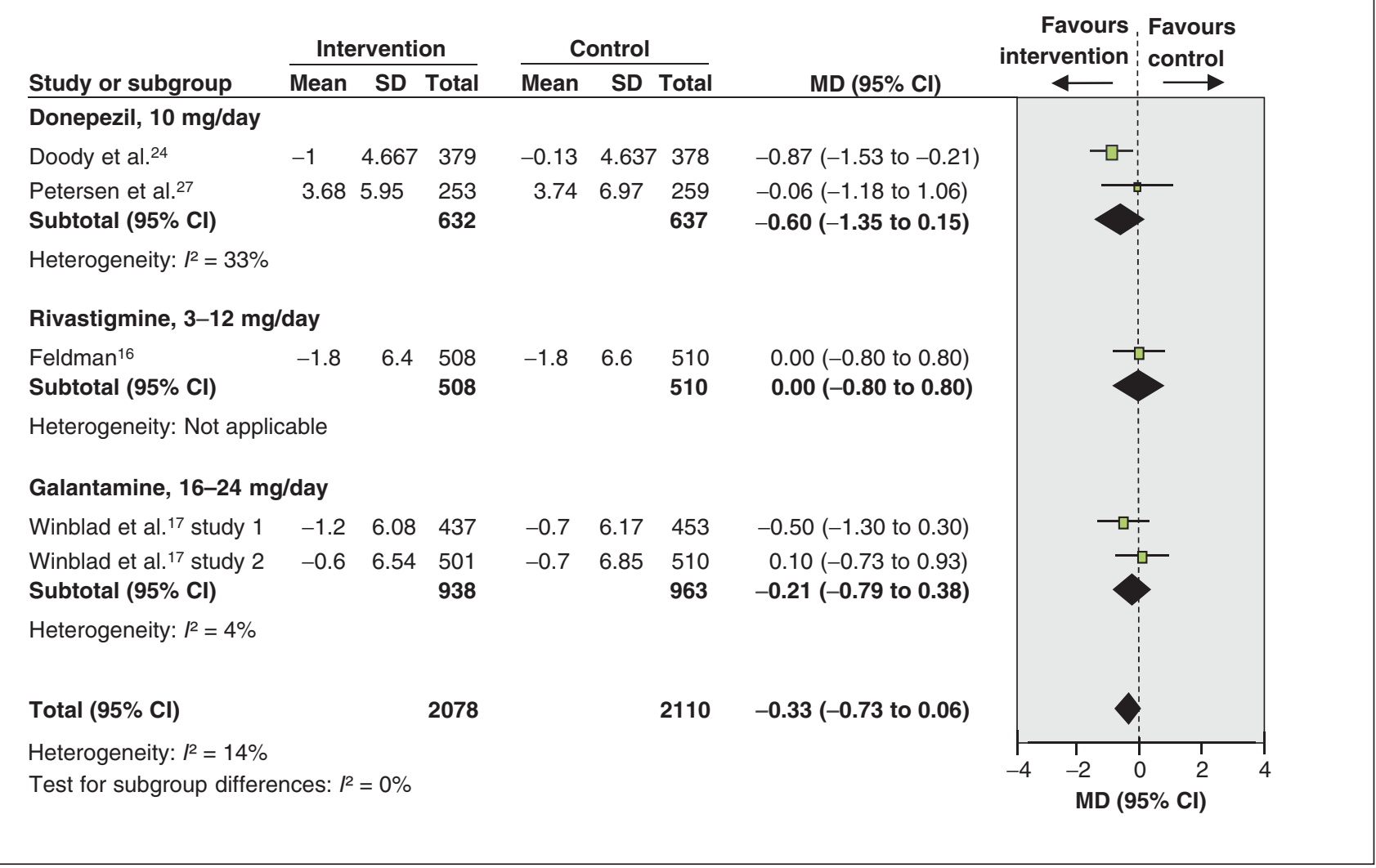

Figure 2: Effects of cholinesterase inhibitors on patient cognition as assessed by the Alzheimer's Disease Assessment Scale, cognition subscale. $\mathrm{Cl}=$ confidence interval, $\mathrm{MD}=$ mean difference.

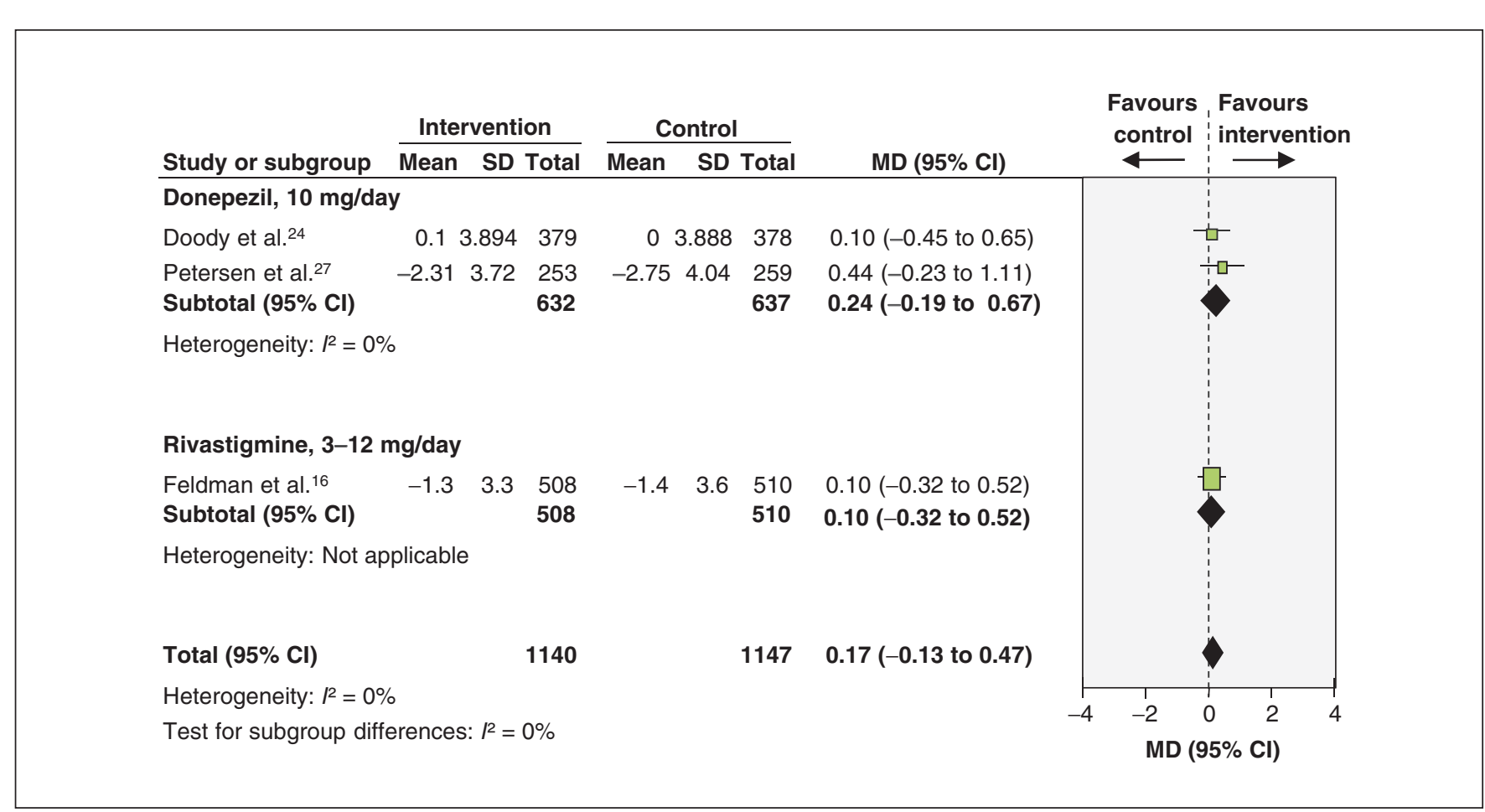

Figure 3: Effects of cholinesterase inhibitors on patient cognition as assessed by the Mini-Mental State Examination. $\mathrm{Cl}=$ confidence interval, $\mathrm{MD}=$ mean difference . 
showed no difference between the intervention and control groups (MD 0.20, 95\% CI -0.04 to 0.43; Figure S4 in Appendix 4). There was high heterogeneity across these studies in terms of both types of dietary supplements or vitamins and dosages.

\section{Secondary outcomes}

Two of the 4 pharmacologic studies reported behaviour using the Neuropsychiatric Inventory tool, and the pooled effect estimate showed no difference between the intervention and control groups (MD 0.12, 95\% CI -0.93 to 1.17 ). ${ }^{16,24}$

One of the studies involving donepezil reported on the outcome of global status using the Clinician's Interventionbased Impression of Change plus Caregiver tool, and the effect estimate showed no difference between the intervention and control groups (MD 0.00, 95\% CI -0.28 to 0.28 ). ${ }^{24}$

The 3 pharmacologic studies investigating the effects of donepezil,${ }^{27}$ rivastigmine ${ }^{16}$ and galantamine ${ }^{17}$ reported on function using the Alzheimer's Disease Cooperative Study activities of daily living inventory tool, and the pooled effect estimate showed no difference between the intervention and control groups (MD 0.20, 95\% CI -0.28 to 0.69 ).

The study evaluating the effect of vitamin E (2000 IU) in combination with a multivitamin (containing 15 IU vitamin E) taken daily reported on function using the Alzheimer's
Disease Cooperative Study activities of daily living inventory tool, and the effect estimate showed no difference between intervention and control groups (MD $0.76,95 \% \mathrm{CI}-0.77$ to 2.29). ${ }^{27}$

\section{Serious adverse events}

For the outcome of serious adverse events, the quality of the body of evidence was low (Appendix 3; Figure 4). No studies reported on death.

Five studies evaluated serious adverse events that occurred as a result of pharmacologic treatments: 3 involved donepezil $(10 \mathrm{mg} / \mathrm{d}),{ }^{24,27,28} 1$ involved rivastigamine $(3-12 \mathrm{mg} / \mathrm{d})^{16}$ and 1 involved galantamine $(8-16 \mathrm{mg} / \mathrm{d}) \cdot{ }^{17}$ The pooled effect estimate showed no difference in serious adverse events for intervention, when compared with control groups (risk ratio 0.98, $95 \%$ CI 0.86 to 1.10$)$.

Four studies reported no serious adverse events as a result of behavioural interventions. ${ }^{20,25,29,30}$ All 4 studies focused on exercise interventions.

Three studies reported no serious adverse events as a result of using dietary supplements or vitamins. ${ }^{27,31,32}$ One study evaluated 2 daily doses of capsules containing docosahexaenoic $(720 \mathrm{mg})$, eicosapentaenoic acid $(286 \mathrm{mg})$, vitamin $\mathrm{E}$ $(16 \mathrm{mg})$, soy phospholipids (160 mg), tryptophan $(95 \mathrm{mg})$ and melatonin $(5 \mathrm{mg}) ;{ }^{31} 1$ study evaluated a daily dose of vitamin

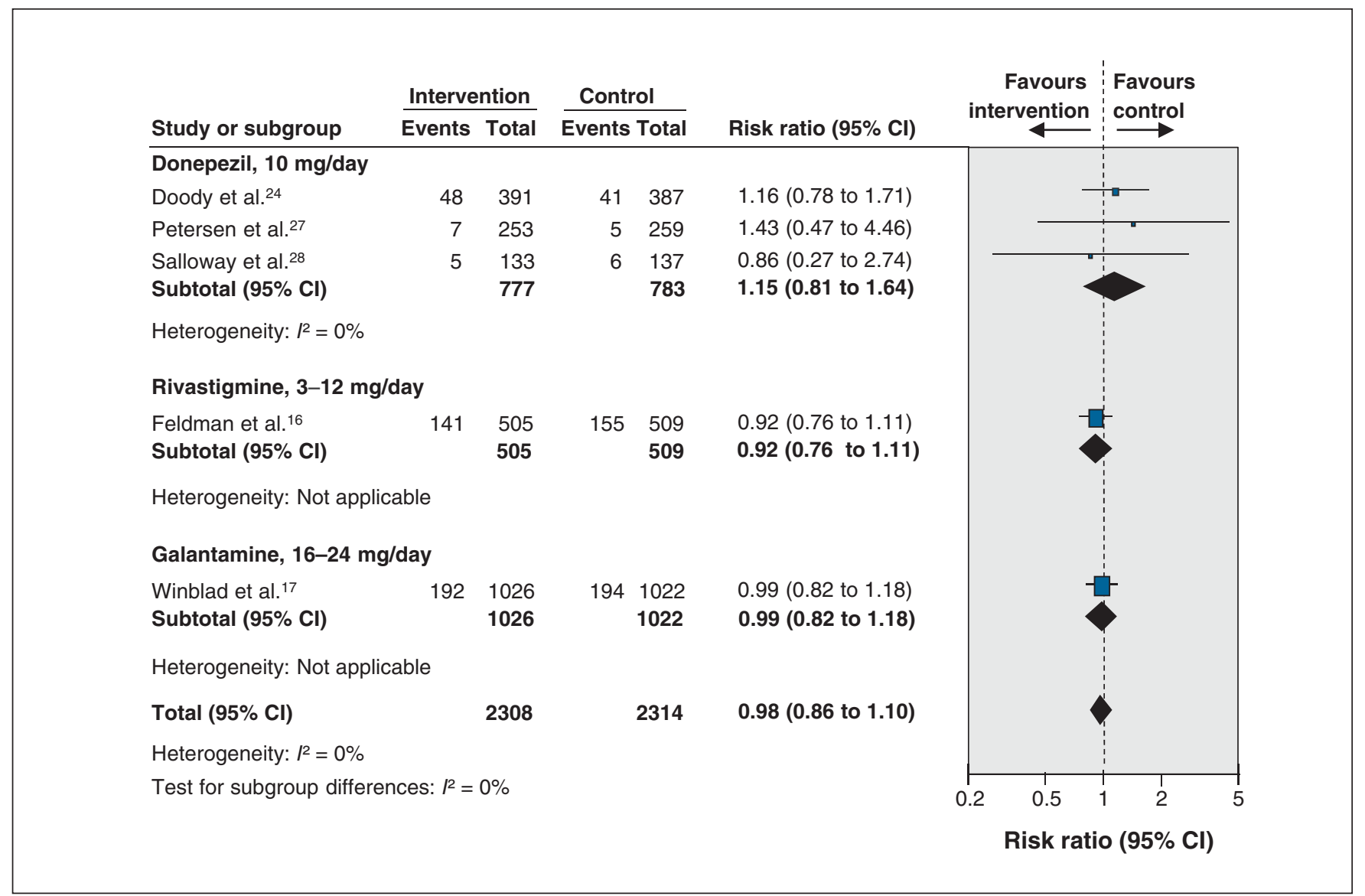

Figure 4: Serious adverse events associated with the use of cholinesterase inhibitors in patients with mild cognitive impairment. $\mathrm{Cl}=$ confidence interval. 
$\mathrm{E}(2000 \mathrm{IU})$ in combination with a multivitamin (containing $15 \mathrm{IU}$ vitamin $\mathrm{E}) ;{ }^{27}$ and 1 study evaluated the use of lyophilized royal jelly $(750 \mathrm{mg})$ in combination with ginkgo biloba $(120 \mathrm{mg})$ and panax ginseng $(150 \mathrm{mg}){ }^{32}$

\section{Interpretation}

\section{Main findings}

We found no evidence of benefit from the pharmacologic treatment for mild cognitive impairment. We observed a small but significant benefit to cognition (as measured using the Mini-Mental State Examination) for nonpharmacologic treatments (i.e., multicomponent exercise programs, cogintiv etraining and rehabilitation) compared with the no-treatment control group.

\section{Explanation and comparison with other systematic reviews}

We evaluated the evidence for pharmacologic and nonpharmacological interventions for mild cognitive impairment, whereas the review by Lin and colleagues evaluated interventions for cognitive impairment and dementia. ${ }^{7}$ Unlike Lin and colleagues, who found a small benefit in treating all types of cognitive impairment, our review did not find a benefit with pharmacotherapy for mild cognitive impairment, suggesting that the benefit of treatment for cognitive impairment with pharmacotherapy may be primarily for those with more severe types of impairment. This is consistent with earlier reviews that found no benefit for the treatment of mild cognitive impairment with cholinesterase inhibitors. ${ }^{8,33}$ Finally, our review builds on the recent meta-analysis by Tricco and colleagues, ${ }^{8}$ which examined the benefit of pharmacotherapy in mild cognitive impairment. Our review adds to the literature by including nonpharmacologic interventions that appear to have small but uncertain benefits for community-dwelling older adults with mild cognitive impairment.

\section{Limitations}

Although our search was comprehensive, it is possible that we could have missed potentially relevant studies published in a language other than English or French. The population of interest was adults aged 65 years and older with a diagnosis of mild cognitive impairment. This represents a diverse patient population, and the inclusion criteria (i.e., the definition of mild cognitive impairment applied) may have differed among studies. Finally, there were insufficient studies reporting outcomes of interest to assess publication bias.

In this review, 7 pharmacologic studies used 2 different outcome tools (Alzheimer's Disease Assessment Scale, cognition subscale, and Mini-Mental State Examination) to assess the impact on cognition, which limited the ability to make comparisons across studies.

\section{Conclusion and implications for practice and future research}

Cognitive impairment is a growing concern because of aging populations worldwide. This review adds to the body of evi- dence related to treating mild cognitive impairment. This review found no evidence for the benefit of pharmacologic interventions, including cholinesterase inhibitors, in the treatment for mild cognitive impairment on any relevant outcomes and does not support their use. and small benefits in cognition for nonpharmacologic interventions. The current evidence showed a small benefit in cognition for behavioural interventions; however, the clinical significance of this small benefit remains uncertain, and future high-quality research using a standardized approach is needed to affirm these findings.

\section{References}

1. Dementia numbers in Canada. Toronto: Alzheimer Society Canada; 2015. Available: www.alzheimer.ca/en/About-dementia/What-is-dementia/Dementia -numbers (accessed 2015 Nov. 10).

2. Anderson N, Murphy K, Troyer A. Living with mild cognitive impairment: a guide to maximizing brain health and reducing risk of dementia. Toronto: Baycrest Health Sciences; 2015. Available: www.baycrest.org/about/publications/healthcare -professionals/living-with-mci/ (accessed 2015 Apr. 13).

3. Moyer VA; U.S. Preventive Services Task Force. Screening for cognitive impairment in older adults: U.S. Preventive Services Task Force recommendation statement. Ann Intern Med 2014;160:791-7.

4. Reisberg B, Ferris SH, de Leon MJ, et al. Stage-specific behavioral, cognitive, and in vivo changes in community residing subjects with age-associated memory impairment and primary degenerative dementia of the Alzheimer type. Drug Develop Res 1988;15:101-14.

5. Ganguli M, Snitz BE, Saxton JA, et al. Outcomes of mild cognitive impairment by definition: a population study. Arch Neurol 2011;68:761-7.

6. Golomb J, Kluger A, Ferris SH. Mild cognitive impairment: historical development and summary of research. Dialogues Clin Neurosci 2004;6:351-67.

7. Lin JS, O'Connor E, Rossom RC, et al. Screening for cognitive impairment in older adults: an evidence update for the U.S. Preventive Services Task Force. Rockville (MD): Quality Agency for Healthcare Research; 2013.

8. Tricco AC, Soobiah C, Berliner S, et al. Efficacy and safety of cognitive enhancers for patients with mild cognitive impairment: a systematic review and meta-analysis. CMA7 2013;185:1393-401.

9. Shamseer L, Moher D, Clarke M, et al. Preferred reporting items for systematic review and meta-analysis protocols (PRISMA-P): elaboration and explanation. BM7 2015:349:g7647.

10. Higgins JPT, Altman DG, Sterne JAC, et al. Assessing risk of bias in included studies. In: Higgins JPT, Green S., editors. Cochrane handbook for systematic reviews of interventions, version 5.1.0 [updated March 2011]. London (UK): The Cochrane Collaboration; 2011.

11. GRADE Working Group. Available: www.gradeworkinggroup.org/ (accessed 2015 Nov. 10).

12. DerSimonian R, Laird N. Meta-analysis in clinical trials. Control Clin Trials 1986;7:177-88.

13. Cochrane handbook for systematic reviews of interventions, version 5.1.0 [updated March 2011]. London (UK): The Cochrane Collaboration; 2011.

14. Deeks JJ, Higgins JP, Altman DG; The Cochrane Statistical Methods Group, editors. Chapter 16: Special topics in statistics. In: Cochrane handbook for systematic reviews of interventions, version 5.1.0 [updated March 2011]. London (UK): The Cochrane Collaboration; 2011.

15. Moher D, Liberati A, Tetzlaff J, et al. Preferred Reporting Items for Systematic reviews and Meta-analyses: the PRISMA statement. Open Med 2009; 3:e123-30.

16. Feldman HH, Ferris S, Winblad B, et al. Effect of rivastigmine on delay to diagnosis of Alzheimer's disease from mild cognitive impairment: the InDDEx study. Lancet Neurol 2007;6:501-12.

17. Winblad B, Gauthier S, Scinto L, et al. Safety and efficacy of galantamine in subjects with mild cognitive impairment. Neurology 2008;70:2024-35.

18. Suzuki T, Shimada H, Makizako H, et al. Effects of multicomponent exercise on cognitive function in older adults with amnestic mild cognitive impairment: a randomized controlled trial. BMC Neurol 2012;12:128.

19. Tsolaki M, Kounti F, Agogiatou C, et al. Effectiveness of nonpharmacological approaches in patients with mild cognitive impairment. Neurodegener Dis 2011; $8: 138-45$.

20. Wei XH, Ji LL. Effect of handball training on cognitive ability in elderly with mild cognitive impairment. Neurosci Lett 2014;566:98-101.

21. Rojas GJ, Villar V, Iturry $M$, et al. Efficacy of a cognitive intervention program in patients with mild cognitive impairment. Int Psychogeriatr 2013;25:825-31.

22. Lee LK, Shahar S, Chin A-V, et al. Docosahexaenoic acid-concentrated fish oil supplementation in subjects with mild cognitive impairment (MCI): a 12-month randomised, double-blind, placebo-controlled trial. Psychopharmacology (Berl) 2013;225:605-12.

23. Naeini AM, Elmadfa I, Djazayery A, et al. The effect of antioxidant vitamins 
$\mathrm{E}$ and $\mathrm{C}$ on cognitive performance of the elderly with mild cognitive impairment in Isfahan, Iran: a double-blind, randomized, placebo-controlled trial. Eur 7 Nutr 2014;53:1255-62.

24. Doody RS, Ferris SH, Salloway S, et al. Donepezil treatment of patients with MCI: a 48-week randomized, placebo-controlled trial. Neurology 2009; 72:1555-61.

25. Suzuki T, Shimada H, Makizako H, et al. A randomized controlled trial of multicomponent exercise in older adults with mild cognitive impairment. PLOS ONE 2013;8:e61483.

26. de Jager CA, Oulhaj A, Jacoby R, et al. Cognitive and clinical outcomes of homocysteine-lowering B-vitamin treatment in mild cognitive impairment: a randomized controlled trial. Int 7 Geriatr Psychiatry 2012;27:592-600.

27. Petersen RC, Thomas RG, Grundman M, et al. Vitamin E and donepezil for the treatment of mild cognitive impairment. N Engl 7 Med 2005;352:2379-88.

28. Salloway S, Ferris S, Kluger A, et al. Efficacy of donepezil in mild cognitive impairment: a randomized placebo-controlled trial. Neurology 2004; 63:651-7.

29. Tsai PF, Chang JY, Beck C, et al. A pilot cluster-randomized trial of a 20-week Tai Chi program in elders with cognitive impairment and osteoarthritic knee: effects on pain and other health outcomes. 7 Pain Symptom Manage 2013;45:660-9.

30. van Uffelen JG, Chinapaw MJ, van Mechelen W, et al. Walking or vitamin B for cognition in older adults with mild cognitive impairment? A randomised controlled trial. Br 7 Sports Med 2008;42:344-51.

31. Rondanelli M, Opizzi A, Faliva M, et al. Effects of a diet integration with an oily emulsion of DHA-phospholipids containing melatonin and tryptophan in elderly patients suffering from mild cognitive impairment. Nutr Neurosci 2012;15:46-54.

32. Yakoot M, Salem A, Helmy S. Effect of Memo®, a natural formula combination, on Mini-Mental State Examination scores in patients with mild cognitive impairment. Clin Interv Aging 2013;8:975-81.

33. Russ TC, Morling JR. Cholinesterase inhibitors for mild cognitive impairment. Cochrane Database Syst Rev 2012;(9):CD009132.

Affiliations: McMaster Evidence Review and Synthesis Centre (MERSC) (Fitzpatrick-Lewis, Warren, Ali, Sherifali, Raina), McMaster University; School of Nursing, Faculty of Health Sciences (Fitzpatrick-Lewis, Warren, Sherifali), McMaster University; Department of Clinical Epidemiology \&
Biostatistics (Ali, Raina), Faculty of Health Sciences, McMaster, University, Hamilton, Ont

Contributors: All of the authors performed tasks involved in conducting the full systematic review. All of the authors reviewed, contributed revisions, gave final approval of the version to be published and agreed to act as guarantors of the work.

Funding: Funding for the McMaster Evidence Review and Synthesis Centre (ERSC) was provided by the Public Health Agency of Canada (PHAC) and the Canadian Institutes of Health Research. The views of the funding bodies have not influenced the content of the review or the decision to submit the paper for publication. The views expressed in this article are those of the authors and do not necessarily represent those of the funders.

Acknowledgements: The authors are grateful to Sharon Peck-Reid, Maureen Rice, Meghan Kenny and Leslea Peirson (members of the ERSC) for their support on this work, including database management and formatting (S.P.R.), conducting the search (M.R.) and screening and extraction (M.R., M.K., L.P.). The authors also thank Alejandra Jaramillo (PHAC) for contributing to the original protocol development and reviewing drafts of the technical report; Rana Rahal (PHAC) for reviewing drafts of the technical report; and Kevin Pottie, Maria Bacchus, Neil Bell, Richard Birtwhistle, Ainsley Moore, Harminder Singh and Marcello Tonelli (members of the Mild Cognitive Impairment Working Group of the Canadian Task Force for Preventive Health Care) for providing comments on the protocol, initial analysis and technical report. Parminder Raina holds a Tier 1 Canada Research Chair in Geroscience and the Raymond and Margaret Labarge Chair in Research and Knowledge Application for Optimal Aging. Diana Sherfali acknowledges the Hamilton Health Sciences Foundation for a Research Early Career Award.

Supplemental information: For reviewer comments and the original submission of this manuscript, please see www.cmajopen.ca/content/3/4/ E419/suppl/DC1 